\title{
OCCURRENCES OF EGGS AND LARVAE OF GASTROINTESTINAL NEMATODES IN NAILS OF STREET INHABITANTS IN DHAKA CITY
}

\author{
Hamida Khanum*, Md. Riajul Islam and Safia Parvin \\ Department of Zoology, University of Dhaka, Dhaka 1000, Bangladesh \\ *Corresponding author; email: hamida_khanum@yahoo.com
}

\begin{abstract}
This study was carried out during the months of May and August, 2008 to determine the prevalence of eggs and larvae of gastrointestinal nematodes in nails of children, mother, venders and rickshaw pullers in Dhaka city. Out of 120 individuals, 77 were infected with different nematodes and the prevalence was 64.16\%. Ascaris lumbricoides infestation was positive for 39 persons (50.65\%), Trichuris trichiura for 18 (23.37\%) and Ancylostoma duodenale for 20 (25.97\%). Prevalence of nematode parasites in left hand of children in the age group 2-4 years had the highest prevalence (80\%) in comparison with the left hand of the rickshaw pullers $(75.75 \%)$. The highest infection was $80 \%$ among the people who used to wash their hands with only water after defaecation, $72.22 \%$ who washed their hands with soil and water, and only $12.5 \%$ who washed with soap and water. It was also found that 61 peoples did not cut their nails regularly and the infection rate was $79.22 \%$. On the other hand, those who cut their nails regularly, the infection rate were $37.20 \%$. A higher rate of infestation was thus found to be associated with poor socioeconomic conditions, poor sanitation, poor ecological conditions, general ignorance, unawareness of personal hygiene and miscellaneous bad habits.
\end{abstract}

Key words: Gastrointestinal nematodes, eggs and larvae, nails, street inhabitants, Dhaka City.

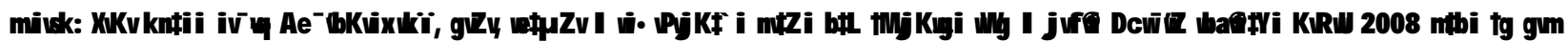

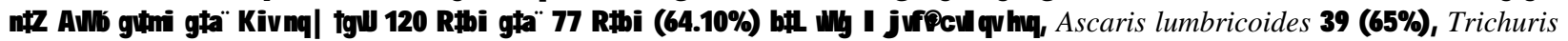

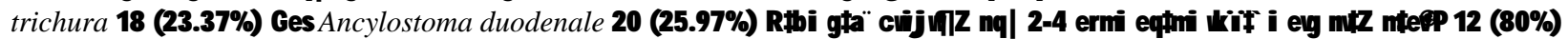

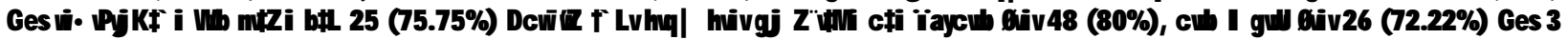

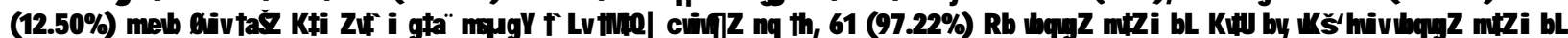

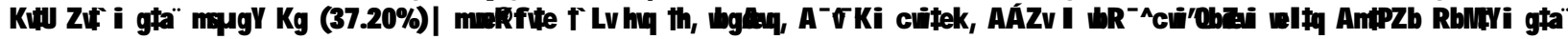

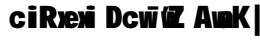

\section{Introduction}

Human intestinal parasites, especially nematodes are transmitted by various ways. Transmission of the egg and larval stages of the parasites to the final host (human) in the developmental cycles is accomplished by three methods (Mottalib, 1976). Passive transmission occurs when the infective stages of the parasites contaminate or infect the food or water of the host and are swallowed with them. Human sewerage and slug are often rained into soil. These soil transmitted nematode ova pass through human stool and become highly infective after 2-3 weeks' incubation in the soil and can easily be transmitted to healthy individuals frequently by oral-faecal route (Parvin et al. 2010). Reports from various studies of intestinal parasites worldwide, especially from the tropical countries and costal regions, showed that the roundworm Ascaris lumbricoides, the whipworm Trichuris trichiura and the hookworms Ancylostoma duodenale are three commonly prevalent intestinal nematodes of major public health significance (WHO 1992, 1994).

Although not a killing disease, helminthiasis causes debilitating effects on the community which are disastrous in term of efficiency of manpower, decreased body resistance, retardation of physical and mental development, increased morbidity rate, greater incidence of abortion, sterility, stillbirth, impaired lactation and increased susceptibility to various nonhelminthic diseases. Crompton et al. (1989) and Crompton (2000) reported 335, 220 and 159 million morbidity for As. lumbricoides, T. trichiura and hookworm, respectively. They found the highest mortality (65 thousands/year) due to the infection of hookworm followed by As. lumbricoides (60 thousands/year) and $T$. trichiura (10 thousands/year). Besides the above adverse effects, As. lumbricoides, hookworm and T. trichiura are also the causative agent of stunting growth, short memory, anaemia, inferiority in intelligence and thinking capacity of children ( Uddin and Khanum 2005, 2008; Khanum et al. 1997).

A few studies on the epidemiology of intestinal parasites have been carried out in this country. Kuntz (1960) reported the incidence of Ascaris (66\%), Trichuris (76\%) and Ancylostoma (47\%) among the people of Dhaka. Types of house, latrine, barefooted behaviour of the children and illiteracy of the mother were taken as hygienic measures for the hookworm infection (Khanum et al. 2005). 
Dhaka, with increasing inhabitants of more than 15 million, represents a city of highly congested population. A large part of this population resides in the slum areas with very poor living condition, where there is practically no provision for safe water supply and safe excreta disposal system (Khanum and Alam, 2005). Children are the most vulnerable and helpless among all the members of the slum families. They are mostly affected by their living condition in Dhaka city leading to suffer from various diseases and malnutrition. The heavy rainfall, climatic and atmospheric condition, fertile soil, water sources and socio-economic condition of this Megacity are suitable for transmission of parasitic infection. Helminthic infection, especially that of nematodes, is a major health problem of wide spread endemicity in this country. So many factors like poor hygienic habits, poor standard of living, lack of health education, ignorance, poverty, poor socio-economic conditions and general insanity of the majority of the population are obvious causal agents (Khanum et al. 2000). The present study therefore was designed to identify the causes of nematode infection among the people of lower income groups such as street children, mothers, rickshaw pullers and day labours, which may contribute to future planning for prevention of intestinal parasites in our country.

\section{Materials and Methods}

The present study was of a cross sectional type, conducted by interviewing the people to ascertain their perception and nail cutting and hand washing behaviors with regard to helminthes infections among them. It was also aimed to determine the hygienic practices like nail cutting, habituated to unwashed and exposed food items and finger sucking by the respondents. Another aspect of this study was to assess the knowledge of people about common nematode parasites. Dwellers from a street in Dhaka University campus area were selected. The collected specimens were examined in the Parasitological Laboratory, Department of Zoology, University of Dhaka, for examination. This study was carried out from May to August 2008. A total of 120 nail samples were collected randomly. The subjects were interviewed using questionnaire designed for this study.

Filling in the questionnaire: In the beginning the selected people were explained about the nature of the study, assuring them that the study would not be harmful for them, rather it would be helpful to understand their health problems. The questionnaire was filled up by face-to-face interviewing of each people in Bengali, where a local guide provided necessary help. In addition, the demographic, socio-economic and sanitary conditions of the study household were noted. For each respondent, a serial number was maintained.
Collection and processing of the nail samples: Nail samples were collected randomly from 120 inhabitants consisting of children $(n=35)$, mothers $(n=25)$, rickshaw pullers $(n=33)$, other workers $(n=12)$ and day labours $(n=$ 15). Soon after using latrine and before washing hands, the samples were collected from each subject in individual vials in $70 \%$ alcohol. Then the samples were carried to the laboratory for examination under microscope (10× 10 and 40) to record the presence of egg and larval stages of the nematode parasites, if any. The samples were finally processed by direct smear method which has convenience over the concentration method (Cheesbrough 1987).

\section{Results and Discussion}

Occurrence of eggs and larvae of nematode parasites: Out of 120 nail samples, 77 were positive for the ova of As. lumbricoides, T. trichiura and larvae of $A n$. duodenale. The overall infestation rate was $64.16 \%$. (Table 1). Of 77 positive cases (Table 2), the prevalence of As. lumbricoides was the highest (50.65\%), An. duodenale the intermediate (25.97\%) and T. trichiura the lowest (23.37\%).

Table 1. Prevalence of nematode parasites among the inhabitants in the Dhaka University campus

\begin{tabular}{|c|c|c|c|}
\hline Area & $\begin{array}{c}\text { No. sample } \\
\text { examined }\end{array}$ & $\begin{array}{c}\text { No. positive } \\
\text { cases }\end{array}$ & $\begin{array}{c}\% \text { Positive } \\
\text { cases }\end{array}$ \\
\hline $\begin{array}{c}\text { Dhaka } \\
\text { University } \\
\text { campus }\end{array}$ & 120 & 77 & $64.16 \%$ \\
\hline
\end{tabular}

Table 2. Prevalence of eggs and larvae of different matode parasites in nail samples

\begin{tabular}{|c|c|c|}
\hline Parasites & No. infected cases & \% Prevalence \\
\hline A. lumbricoides & 39 & 65.00 \\
\hline T. trichiura & 18 & 23.37 \\
\hline A. duodenale & 20 & 25.97 \\
\hline
\end{tabular}

Table 3. Occurrences of nematode parasitic infestation among the children of different age groups

\begin{tabular}{|c|c|c|c|c|c|c|}
\hline \multirow{2}{*}{$\begin{array}{c}\text { Age groups } \\
\text { (yrs) }\end{array}$} & \multicolumn{3}{|c|}{ Left hand } & \multicolumn{3}{c|}{ Right hand } \\
\cline { 2 - 7 } Examined & $\begin{array}{c}\text { No. } \\
\text { positive } \\
\text { cases }\end{array}$ & $\begin{array}{c}\% \\
\text { Positive } \\
\text { cases }\end{array}$ & $\begin{array}{c}\text { No. } \\
\text { Examined }\end{array}$ & $\begin{array}{c}\text { No. } \\
\text { Positive } \\
\text { cases }\end{array}$ & $\begin{array}{c}\% \\
\text { Positive } \\
\text { cases }\end{array}$ \\
\hline $2-4$ & 15 & 12 & 80.00 & 15 & 10 & 66.67 \\
\hline $4.1-6$ & 6 & 4 & 66.67 & 6 & 3 & 50.00 \\
\hline $6.1-8$ & 10 & 7 & 70.00 & 10 & 4 & 40.00 \\
\hline $8.1-10$ & 4 & 1 & 25.00 & 4 & 1 & 25.00 \\
\hline Total & 35 & 24 & & 35 & 18 & \\
\hline
\end{tabular}


Table 4. Occurrence of larvae and eggs of nematode parasites in left and right hands of the respondents

\begin{tabular}{|c|c|c|c|c|c|c|}
\hline \multirow{2}{*}{ Occupation } & \multicolumn{3}{|c|}{ Left hand } & \multicolumn{3}{c|}{ Right hand } \\
\cline { 2 - 7 } & $\begin{array}{c}\text { No. } \\
\text { example } \\
\text { Camined }\end{array}$ & $\begin{array}{c}\text { No. } \\
\text { cositive } \\
\text { cases }\end{array}$ & $\begin{array}{c}\% \\
\text { Positive } \\
\text { cases }\end{array}$ & $\begin{array}{c}\text { No. } \\
\text { Sample } \\
\text { examined }\end{array}$ & $\begin{array}{c}\text { No. } \\
\text { Positive } \\
\text { cases }\end{array}$ & $\begin{array}{c}\% \\
\text { Positive } \\
\text { cases }\end{array}$ \\
\hline $\begin{array}{c}\text { Rickshaw } \\
\text { pullers }\end{array}$ & 33 & 25 & 75.75 & 33 & 18 & 54.54 \\
\hline Day labour & 15 & 10 & 66.66 & 15 & 6 & 40.00 \\
\hline $\begin{array}{c}\text { Other } \\
\text { workers }\end{array}$ & 12 & 4 & 33.33 & 12 & 1 & 8.33 \\
\hline Mothers & 25 & 15 & 60.00 & 25 & 12 & 48.00 \\
\hline
\end{tabular}

Table 5. Distribution of nematode parasitic infestation according to the method of washing hands after defaecation

\begin{tabular}{|c|c|c|c|c|}
\hline \multirow{2}{*}{$\begin{array}{c}\text { Hand } \\
\text { washing } \\
\text { habits }\end{array}$} & $\begin{array}{c}\text { No. } \\
\text { Examined }\end{array}$ & $\begin{array}{c}\text { No. } \\
\text { Positive } \\
\text { cases }\end{array}$ & $\begin{array}{c}\% \\
\text { Positive } \\
\text { cases }\end{array}$ & $\begin{array}{c}\% \\
\text { Average }\end{array}$ \\
\hline Soap + water & 24 & 3 & 12.50 & \\
\hline Soil + water & 36 & 26 & 72.22 & \multirow{2}{*}{54.90} \\
\hline Only water & 60 & 48 & 80.00 & \\
\hline Total & 120 & 77 & & \\
\hline
\end{tabular}

Table 6. Distribution of nematode parasitic infection in relation to nail cutting habits of the respondents

\begin{tabular}{|c|c|c|c|}
\hline $\begin{array}{c}\text { Nail cutting } \\
\text { habits }\end{array}$ & No. Examined & No. Infected & \% Infection \\
\hline Irregular & 77 & 61 & 79.22 \\
\hline Regular & 43 & 16 & 37.20 \\
\hline Total & 120 & 77 & \\
\hline
\end{tabular}

Table 7. Distribution of nematode parasitic infection in relation to miscellaneous bad habits

\begin{tabular}{|c|c|c|c|}
\hline Bad habits & $\begin{array}{c}\text { No. } \\
\text { Examined }\end{array}$ & $\begin{array}{c}\text { No. Positive } \\
\text { cases }\end{array}$ & \% Prevalence \\
\hline Nail biting & 32 & 25 & 78.15 \\
\hline $\begin{array}{c}\text { Taking unwashed } \\
\text { food }\end{array}$ & 19 & 9 & 47.00 \\
\hline $\begin{array}{c}\text { Taking exposed } \\
\text { food }\end{array}$ & 16 & 11 & 68.75 \\
\hline Sucking finger & 10 & 5 & 50.00 \\
\hline Total & 77 & 50 & \\
\hline
\end{tabular}

Incidence of parasites in children: Nematode infestations in relation to the age groups of children revealed that the prevalence was the highest (80\%) in 24 years age group, and the lowest in 8-10 years age group (25\%). The prevalence was comparatively higher in left hand of the children than the right hand (Table 3). Occupation-dependent incidence of parasites: A total sample of 60 male inhabitants in the street of Dhaka University area was divided into four categories (Table 4). Among 33 rickshaw pullers, nematode infection in the left hand was $75.75 \%$ and that in the right hand was $54.54 \%$. The nematode infection in the left and right hands of other workers was $33.33 \%$ and $8.33 \%$, respectively. Whereas day labours had $66.66 \%$ infection in their left hands and $40 \%$ in right hands. Out of 25 mothers, nails of both left (60\%) and right (48\%) hands were found infected.

Hand washing, nail cutting and other habits: Depending on the hand washing habits (Table 5), 48 positive cases were found $(80 \%)$ who washed their hands with only water, 26 (72.22\%) who washed their hands with soil and water and 3 (12.5\%) who used soap and water. These results suggest that hand washing with soap and water reduces nematode infestation in nails. Of 120 peoples, 61 persons did not cut their nails regularly and the infection rate was $79.22 \%$. On the other hand, in those who used to cut their nails regularly, the infection rate was $37.20 \%$ (Table 6 ), indicating that nail cutting habit is important from personal hygienic point of view.

Miscellaneous bad habits: Data presented in Table 7 show that most of the children had nail biting habits (78\%), followed by taking exposed (68.75\%) and unwashed food (47.00\%) and habit of sucking fingers (50.00\%).

The aim of the present study was to determine the reasons for presence of the nematode parasites among street children, mothers, labourers, venders and rickshaw pullers and to find out the relationship between the infection and their behaviour and also to provide information on mothers' awareness of slum children, where the infection is in epidemic shape. The street children and other people, who live on footpath, do not have sanitary toilets. So, they defaecate beside the footpath areas, little far from their places where they live. They do not wash their hand properly after defaecation and before taking meal. They use simple water or some people use soil and water and very few use soap with water. Because they are so poor, they do not want to spend money for buying soap. Though their hands look apparently clean, parasitic stages of intestinal nematodes remain attached to their nails. During taking meal by such contaminated hands, obviously, they have the infection.

So nail is the main route of contamination in poor class people. Various factors such as washing hands after defaecation, food washing, nail cutting habits and age groups affect the presence of gastrointestinal nematode parasites in a person's nails. In the present research it was found that out of 120 people, 77 peoples were infected, where the prevalence rate was 64.16\%. This result correlates with the study of Khanum et al. (2005) 
in children from two slum areas of Dhaka city, in which a total of 253 faecal specimens were examined to find out the endoparasitic intestinal roundworms As. lumbricoides and T. trichiura. The overall prevalence of As. lumbricoides, T. trichiura and their mixed infections were 34.38, 17.39 and $12.65 \%$, respectively. The prevalence of As. lumbricoides and mixed infection were higher in Mirpur slum area (35.29\% and 14.70\%, respectively) than Agargaon slum area (33.33\% and $10.26 \%$, respectively). On the other hand, the prevalence of $T$. trichiura was higher in Agargaon slum area $(18.80 \%)$ than that in Mirpur slum area. Boys showed a higher prevalence of $T$. trichiura and mixed infection (17.97\% and $14.06 \%$, respectively) than those in girls (16.80\% and $11.20 \%$, respectively). While girls had more prevalence for As. lumbricoides (35.20\%) than that for boys (33.59\%).

Different rates of nematode infections were found in different age groups of children. The prevalence was the highest in 2-4 years age group (80\%) and the lowest in 8-10 years (25\%). Also the prevalence was highest in left hand compared to that in the right hand. Khanum et al. (1999) studied a total of 510 stool samples from the children of age group 2-16 years (irrespective of sex) from the residence of lower class employees of three areas in Dhaka city, where $47.26 \%$ of the children were infested with the nemaodes; out of which $20.39 \%$ were positive for A. lumbricoides infestation, $15.30 \%$ for $T$. trichiura and $11.57 \%$ for mixed infection. In the present investigation age group 4.1-6.0 years had the highest prevalence of $40.78 \%$ for As. lumbricoides and $28.94 \%$ for T. trichiura. Khanum et al. (1997) working on 400 stool samples of children in four slum areas reported that As. lumbricoides (52.58\%) and T. trichiura (27.23\%) were more prevalent in male than in female children. Comparing the highest prevalence of nematode species in different age groups, it was found in the present results that As. lumbricoides had $60.86 \%$ infestation in 2.1-4 years and T. trichiura had $32.43 \%$ in 4.1-6 years age groups.

The common intestinal parasites found in Bangladesh are As. lumbricoides, T. trichiura, An. duodenale and the threadworm Strongyloides stercoralis etc. These parasites may cause mild or severe diseases, generally producing symptoms like abdominal pain and vomiting (Saha and Chowdhury 1961). Strongyloidiasis caused by $S$. stercoralis, like most filth borne diseases, is most prevalent under condition of low sanitation standards. Peoples typically become infected with these parasites by contacting their juvenile in contaminated soil and water (Schmidt and Roberts, 1989) An estimated one billion persons in low-income group of developing countries do not have access to improved drinking water (Rangel et al., 2003). Parvin et al. (2010) reported prevalence of helminthes in a lake of Dhaka city where As. lumbricoides had 100\%, T. trichura, S. stercoralis and hookworms had 25\% cases with eggs and larvae.

Uddin et al. (2005) and Uddin and Khanum (2008) worked on parasitic infestation and anemic status among the adolescent girls and boys in certain rural areas of Bangladesh, and reported single and double infection of gastrointestinal parasites and comparatively higher infestation of hookworm The prevalence of hookworm infection was higher in Kutumbopur (30.0\%) than Gazichat (26.7\%). The prevalence was higher in males than females in both the study areas. The prevalence of the hookworm infection was the highest among the age group of $6.1-8$ yrs (34.28\%) in both the areas and the lowest among the age group 10.1 (7.14\%). Types of house, latrine, bare footed behaviour of the children and illiteracy of the mother were considered as the prime hygienic causes responsible for the hookworm infection.

\section{Conclusion}

The route of transmission is important for many protozoan and helminth parasites, with water, soil and food being particularly significant. The potential for producing large numbers of transmittable stages and their environmental robustness (ability to survive in moist microclimates for prolonged periods of time) pose persistent threats to public health. Increased demands made on natural resources increase the likelihood of encountering environments and produce contaminated with parasites (Smith, 1999).

\section{References}

Cheesbrough M. 1987. Medical Laboratory Manual for Tropical Countries ( $2^{\text {nd }}$ edn). Vol I. English Language Book Society, London. 605 pp.

Crompton DWT. 2000. The public importance of hookworm disease. Parasitol. 121: 30-50.

Crompton DWT, Nesheim MC and Pawlowski Z. 1989. Ascariasis and Its Prevention and Control. Taylor and Francis, London. 200 pp.

Khanum H, Chawdhury S and Bhuiyan ZJ. 1999. Infestation of three intestinal worms in children of three selected rural areas, Bangladesh. Pakistan J. Zool. 31(4): 391-396.

Khanum H, Islam N and Dhar T. 1997, Prevalence of Ascaris lumbricoides and Trichuris trichiura among the children of four slum areas of Dhaka city. Univ. j. zool. Rajshahi Univ. 16: 86-97.

Khanum $\mathrm{H}$ and Alam MS. 2005. Infection of Ascaris lumbricoides and Trichuris trichiura among the children of two slum area in Dhaka city. Bangladesh $J$. Zoo. 33(1): 89-95. 
Khanum H, Chawdhury S and Paul S. 2000. Hookworms infections in as influenced by hygienic and socio-economic condition in some rural areas of Bangladesh. Univ. j. zool, Rajshahi Univ. 19: 83-86.

Khanum H, Islam NM and Nahar NK. 1999 Intestinal nematode infestation in children of lower income group employees in Dhaka city. Bangladesh J. Zool. 27(2): 177-183.

Khanum H, Uddin H and Rahman M. 2005. Hookworm infection and hygienic condition in the rural children of Bangladesh. Bangladesh J. Zool. 33(1): 75-79.

Kuntz RE. 1960. Intestinal protozoa and helminthes in school children in Dhaka. East Pakistan. Amer. J. Trop. Med. Hyg. 19: 168-176.

Muttalib MA. 1976. Prevalence of intestinal parasites in rural children in Bangladesh. Bang. Med. J. 4(1): 15-21.

Parvin $\mathrm{H}$, Uddin $\mathrm{MH}$, Khanum $\mathrm{H}$, Islam MS, Matin MA, Rahman MS, Endtz HP, Cravioto A. and Islam MS. 2010. Prevalence of helminthes in a lake of Dhaka City, Bangladesh. Bangladesh J. Zool. 38(1): 31-39.

Rangel JM, Lopez B, Mejia, MA, Mendoza C and Luby S. 2003. A novel technology to improve drinking water quality: a microbiological evaluation of in-home flocculation and chlorination in rural Guatemala. $J$. Water Health. 1(1): 15-22.
Saha B and Chowdhury AB. 1961. Helminth infection in under five children in Rangpur and Dinajpur districts. Bang. Med. J. 16(2): 7-11.

Schmidt GD and Roberts LS. 1989. Foundations of Parasitology. The CV Mosby Company, London. 750 pp.

Smith HV. 1999. Current status: Detection of parasites in the environment. Parasitol. 117: 113-141.

Uddin HM, Rahman MM and Khanum H. 2005. Haemoglobin level among adolescent girls and its relation to intestinal parasites. Bangladesh J. Zool. 33(2): 183-187.

Uddin HM and Khanum H. 2008. Intestinal parasitic infestation and anaemic status among the adolescent boys in Bangladesh. Univ. j. zool. Rajshahi Univ. 27: 63-65.

World Health Organization (WHO). 1992. The prevalence of anemia in women: a tabulation of available information. $2^{\text {nd }}$ edn. Geneva. 5$12 \mathrm{pp}$.

World Health Organization (WHO). 1994. Report of the WHO informal consultation on hookworm infection and anaemias in girls and women. WHO/CTD/STP/961: 146 pp.

Manuscript received on 2 December 2010 and revised on 28 December 2010. 